\title{
Melatonin exerts an inhibitory effect on insulin gene transcription via MTNR1B and the downstream Raf-1/ERK signaling pathway
}

\author{
YANLIANG LI ${ }^{1 *}$, HUIHUI WU ${ }^{1 *}$, NAIJIA LIU ${ }^{1}$, XINYI CAO $^{1}$, ZHEN YANG $^{2}$, \\ BIN LU ${ }^{1}$, RENMING HU ${ }^{1}$, XUANCHUN WANG ${ }^{1}$ and JIE WEN ${ }^{1}$ \\ ${ }^{1}$ Department of Endocrinology and Metabolism, Huashan Hospital, Fudan University, Shanghai 200040; \\ ${ }^{2}$ Department of Endocrinology, Xinhua Hospital, Shanghai Jiao Tong University \\ School of Medicine, Shanghai 200092, P.R. China
}

Received July 27, 2016; Accepted November 3, 2017

DOI: $10.3892 / \mathrm{ijmm} .2017 .3305$

\begin{abstract}
The pineal hormone melatonin influences the secretion of insulin by pancreatic islets via the G-protein-coupled melatonin receptors 1 and 2 that are expressed in pancreatic $\beta$-cells. Genome-wide association studies indicate that melatonin receptor 1B (MTNR1B) single nucleotide polymorphisms are tightly associated with type 2 diabetes mellitus (T2DM). However, the underlying mechanism is unclear. Raf-1 serves a critical role in the mitogen-activated protein kinase (MAPK) pathways in $\beta$-cell survival and proliferation and, therefore, may be involved in the mechanism by which melatonin impacts on T2DM through MTNR1B. In the present study, the mRNA expression of the two mouse insulin genes Ins1 and Ins2 was investigated in MIN6 cells treated with different concentrations of melatonin, and insulin secretion was detected under the same conditions. Following the overexpression or silencing of MTNR1B, the activities of components of the MAPK signaling pathway, including Raf-1 and ERK, were evaluated. The impact of MTNR1B knockdown on the melatonin-regulated insulin gene expression and insulin secretion were also investigated. The results demonstrated that exogenous melatonin inhibited the expression of insulin mRNA in the MIN6 cells. Insulin secretion by the MIN6 cells, however, was not affected by melatonin. The MAPK signaling pathway was inhibited in MIN6 cells by treatment with melatonin or the overexpression of MTNR1B. The knockdown of MTNR1B totally attenuated the regulating effect of melatonin on insulin gene expression.
\end{abstract}

Correspondence to: Dr Xuanchun Wang or Professor Jie Wen, Department of Endocrinology and Metabolism, Huashan Hospital, Fudan University, 12 Wulumuqi Middle Road, Shanghai 200040, P.R. China

E-mail: wangxch@fudan.edu.cn

E-mail:wenjie065@126.com

*Contributed equally

Key words: melatonin receptor 1B, pancreatic $\beta$-cells, Raf-1
Additionally, the inductive effect of melatonin on the expression of insulin mRNA was attenuated when the activities of Raf-1 or ERK were blocked using the chemical inhibitors GW5074 and U0126, respectively. It may be concluded that melatonin exerts an inhibitory effect on insulin transcription via MTNR1B and the downstream MAPK signaling pathway.

\section{Introduction}

Genome-wide association studies (GWAS) in large cohorts with varying genetic backgrounds (1-3) have revealed that common variants of melatonin receptor 1B (MTNR1B), the gene encoding melatonin receptor 2 (MT2) have a high and reproducible association with a higher risk of impaired insulin secretion and increased fasting glucose levels. Particularly, when compared with 43 other glycemia-associated genetic loci, the MTNR1B variant appears to carry the strongest effect on diminished glucose-stimulated insulin secretion (GSIS) in isolated human islets (3). The present research group demonstrated for the first time that the MTNR1B rs10830963(G/C) variant is strongly associated with type 2 diabetes mellitus (T2DM) in Han Chinese individuals (4). Therefore, the MTNR1B gene is widely accepted as a diabetes risk gene.

Melatonin (5-methoxy-N-acetyltryptamine) is a hormone synthesized by the circadian system (5) that provides timing cues to tissues expressing melatonin receptors (6). The endocrine pancreatic islet is known as an important melatonin target tissue that expresses melatonin receptors MT1 and MT2 in rodents and humans $(7,8)$. It has been shown that melatonin and insulin secretion have an inverse association (9). Rats and patients with T2DM exhibit decreased melatonin levels and slightly increased insulin levels $(10,11)$

It has been reported that growth factors, nutrients and hormones, including insulin-like growth factor-1, incretins, glucose, triiodothyronine, prolactin and insulin, require activation of extracellular signal-regulated kinase (ERK)1/2 and the phosphoinositide 3-kinase (PI3K)/Akt/mechanistic target of rapamycin signaling pathways to fully induce rodent $\beta$-cell replication $(12,13)$. ERK1/2 are important for insulin gene transcription in pancreatic $\beta$-cells, which produce insulin in 
response to increases in the levels of circulating glucose in order to enable efficient glucose utilization and storage (14). Various factors, including Raf-1(15), Src and sedoheptulokinase(16), have been indicated to induce ERK1/2 to activate a downstream effect, among which Raf-1 is one of the potential activators of ERK1/2.

The Raf/mitogen-activated protein kinase (MAPK)/ERK arm of the insulin signaling pathway serves critical roles in $\beta$-cell survival and proliferation (17). Alejandro et al (15) demonstrated that low doses of insulin rapidly activated Raf-1 in human islets and MIN6 cells, and revealed that the phosphorylation of ERK by insulin was eliminated by exposure to a Raf inhibitor (GW5074) or transfection with a dominant-negative Raf-1 mutant. A study conducted by Pardo et al (18) revealed that adult Raf-1 kinase inhibitor protein 1 knockout mice exhibit a rapid reversal of streptozotocin-induced diabetes compared with control mice. Taking the aforementioned findings into consideration, it is unclear whether Raf-1/ERK pathway activation is affected by melatonin and its receptor MTNR1B in pancreatic $\beta$-cells, and consequently influences insulin synthesis and secretion.

Therefore, the present study explored the role of melatonin and its receptor in the regulation of the Raf-1/ERK pathway as well as insulin synthesis and secretion in MIN6 mouse insulinoma cells.

\section{Materials and methods}

Cell culture. MIN6 cells, a mouse pancreatic $\beta$-cell line, were generously provided by Dr Yang of Joslin Diabetes Center (Harvard Medical School, Boston, MA, USA). The MIN6 cells were cultured in Dulbecco's modified Eagle's medium (DMEM, containing $25 \mathrm{mM}$ glucose, $4.0 \mathrm{mM}$ L-glutamine and $1.0 \mathrm{mM}$ sodium pyruvate; Invitrogen; Thermo Fisher Scientific, Inc., Waltham, MA, USA) 15\% fetal bovine serum (FBS; Invitrogen; Thermo Fisher Scientific, Inc.), $2.5 \mathrm{mM} \beta$-mercaptoethanol, $100 \mathrm{U} / \mathrm{ml}$ penicillin and $100 \mu \mathrm{g} / \mathrm{ml}$ streptomycin (Gibco; Thermo Fisher Scientific, Inc.) at $37^{\circ} \mathrm{C}$ in $5 \% \mathrm{CO}_{2}$. When the cells reached $65 \%$ attachment, they were synchronized using serum-free medium for $8 \mathrm{~h}$. Insulin concentrations were measured in the supernatants following various incubation experiments via ELISA (cat. no. 90080; Crystal Chem, Inc., Downers Grove, IL, USA).

Chemicals and reagents. Antibodies targeting the following proteins were obtained from Cell Signaling Technology, Inc. (Danvers, MA, USA): Phospho-Src (Tyr416; cat. no. 6943), total-Src (cat. no. 2108), phospho-Raf-1 (Ser338; cat. no. 9427), phospho-Raf-1 (Ser259; cat.no.9421), total-Raf-1 (cat.no.9422), phospho-ERK (cat. no. 4370) and $\beta$-actin (cat. no. 4970). Antibodies targeting MTNR1B (cat. no. ABT1890), ERK inhibitor (U0126) and GW5074 were purchased from Sigma-Aldrich (Merck KGaA, Darmstadt, Germany).

Reverse transcription-quantitative polymerase chain reaction (RT-qPCR) analysis. The MIN6 cells were exposed to melatonin at concentrations of $0.01,0.1,1,10$ and $100 \mu \mathrm{M}$ for 3 or $6 \mathrm{~h}$. In subsequent inhibition experiments, $10 \mu \mathrm{M}$ U0126, $5 \mu \mathrm{M}$ GW5074 or $0.1 \%$ dimethylsulfoxide control was added to the medium 30 min prior to cell stimulation with melatonin. Following the treatments, total cellular RNA was extracted from the cells using TRIzol reagent (Invitrogen; Thermo Fisher Scientific, Inc.). The samples were treated with reverse transcriptase kit (cat. no. 4374966; Thermo Fisher Scientific, Inc.) to synthesize cDNA. The reverse transcription was performed sequentially as follows: $25^{\circ} \mathrm{C}$ for $10 \mathrm{~min}, 37^{\circ} \mathrm{C}$ for $120 \mathrm{~min}, 85^{\circ} \mathrm{C}$ for $5 \mathrm{~min}$. qPCR was then performed with SYBR-Green Master mix on an ABI 7000 sequence detection system (both Applied Biosystems; Thermo Fisher Scientific, Inc.). The mRNA levels of the mice genes, insulin 1 (Ins1) and insulin 2 (Ins2), were normalized according to the levels of GAPDH. Primer sequences were as follows: Ins1 forward, 5'-CGTGTAAATGCCACTGAAGC-3' and reverse, 5'-CGGATGGACTGTTTGTAACCT-3'; Ins2 forward 5'-CTTCAGCCCCTCTGGCCATC-3' and reverse, 5'-GAAACAATGACCTGCTTGCTGAT-3'; GAPDH forward, 5'-AACTTTGGCATTGTGGAAGG-3' and reverse, 5'-ACACATTGGGGGTAGGAACA-3'. PCR cycling conditions were as follows: Pre-incubation at $95^{\circ} \mathrm{C}$ for $10 \mathrm{~min}$, followed by 40 cycles of denaturation for $15 \mathrm{sec}$ at $95^{\circ} \mathrm{C}$, annealing for $60 \mathrm{sec}$ at $60^{\circ} \mathrm{C}$, and extension for $60 \mathrm{sec}$ at $72^{\circ} \mathrm{C}$; and finally, termination for $8 \mathrm{~min}$ at $72^{\circ} \mathrm{C}$. The expression levels of target genes were quantified according to the $2^{-\Delta \Delta \mathrm{Cq}}$ method as previously described (19).

Western blot analysis. Following the various treatments, cells were harvested with radioimmunoprecipitation assay lysis buffer (Beyotime Institute of Biotechnology, Jiangsu, China) at $4^{\circ} \mathrm{C}$ and lysates were centrifuged at $12,000 \mathrm{x} \mathrm{g}$ for $10 \mathrm{~min}$. $5 \mathrm{X}$ sodium dodecyl sulfate (SDS) loading buffer (Beyotime Institute of Biotechnology) was added to the supernatant prior to denaturation at $100^{\circ} \mathrm{C}$ for $10 \mathrm{~min}$. A BCA kit (Beyotime Institute of Biotechnology) was used to determine the protein concentration in the supernatant.

Following this, the protein extracts were separated $(50 \mu \mathrm{g}$ each sample) using 10\% SDS-PAGE and transferred onto a polyvinylidene difluoride membrane. The membranes were blocked in Tris-buffered saline containing $0.05 \%$ Triton X-100 and $4 \%(\mathrm{w} / \mathrm{v})$ milk for $2 \mathrm{~h}$ at room temperature. The membrane was incubated for $2 \mathrm{~h}$ at room temperature with anti- $\beta$-actin (dilution, 1:5,000) antibody or overnight at $4^{\circ} \mathrm{C}$ with the other primary antibodies. The membranes were then incubated with secondary antibodies (cat. no. sc2955; dilution, 1:5,000; Santa Cruz Biotechnology, Inc., Santa Cruz, CA, USA) for $1 \mathrm{~h}$ at room temperature. Visualization using enhanced chemiluminescence (Bio-Rad Laboratories, Inc., Hercules, CA, USA) was performed. Protein expression levels were quantified by scanning the immunostaining bands and analyzing using LabWork 4.5 image analysis software (UVP, LLC, Upland, CA, USA). Each experiment was performed at least three times

Plasmid package and transfection. To overexpress MTNR1B in MIN6 cells, the plasmid GV341-MTNR1B was constructed. The cDNA sequence of human MTNR1B was amplified and sub-cloned into the AgeI and NheI sites of the GV341 vector (Genomeditech, Shanghai, China) using the following primers: Forward 5'-TCCGGAACGCAGGTAATTTGT-3' and reverse 5'-GCCCAGCCGTCATAGAAGAT-3'. The primers were synthesized by Shanghai GeneChem Co., Ltd. (Shanghai, China). For short hairpin RNA (shRNA) vector construction, pairs of complementary oligonucleotides interfering with MTNR1B (shMTNR1B-1, shMTNR1B-2, and shMTNR1B-3) were synthesized by Shanghai GeneChem Co., Ltd., annealed, and ligated into vector GV248 (Genomeditech). The targeting sequences of MTNR1B were as follows: shMTNR1B-1, AGC 

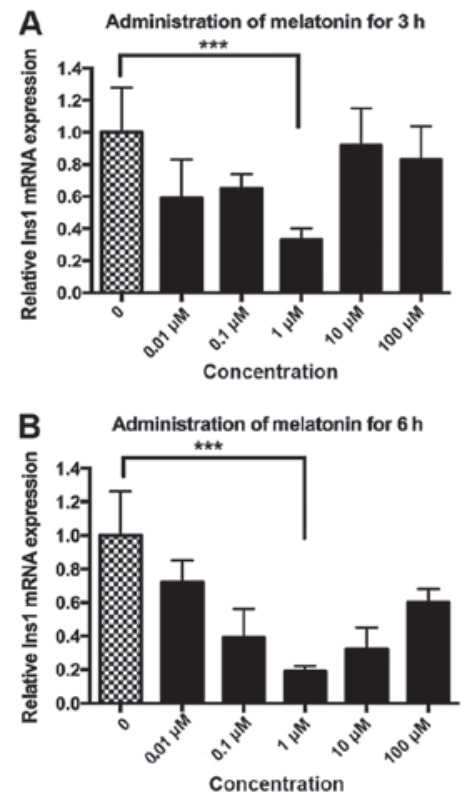

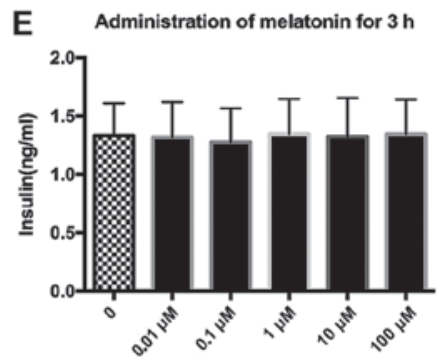

Concentration

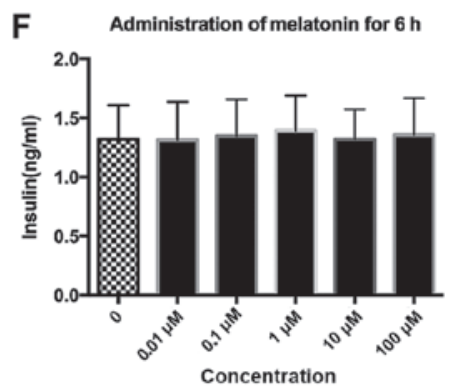

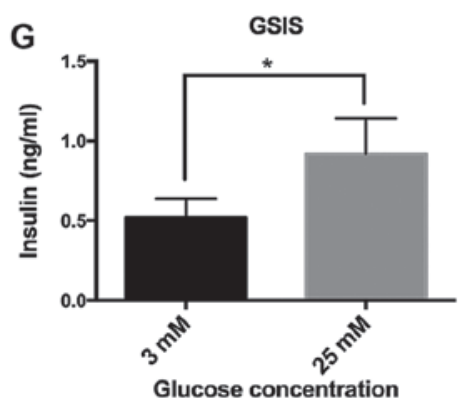

Figure 1. Effects of melatonin on insulin gene transcription and insulin secretion. MIN6 cells were exposed to melatonin at concentrations of $0.01,0.1,1,10$, and $100 \mu \mathrm{M}$ for 3 and $6 \mathrm{~h}$, respectively. The mRNA levels of (A and B) Ins1 and (C and D) Ins2 were determined by reverse transcription-quantitative polymerase chain reaction. (E and F) Insulin levels in the culture medium were measured using ELISA. (G) GSIS was performed on MIN6 cells in vitro and insulin concentrations in the supernatants were measured using ELISA. ${ }^{* *} \mathrm{P}<0.01$ and ${ }^{* * * *} \mathrm{P}<0.001$ as indicated. Ins1, insulin 1; Ins2, insulin 2; GSIS, glucose-stimulated insulin secretion.

TACTTACTGGCTTATT; shMTNR1B-2, AACCATGTT TGTGGTGTTT; and shMTNR1B-3, GAGCTTTCTAACCAT GTTT. A non-targeting scrambled siRNA sequence (TTC TCCGAACGTGTCACGT) was used as a control.

For plasmid transfection, MIN6 cells were seeded into a six-well plate with a density of $5 \times 10^{5}$ cells/well. After $24 \mathrm{~h}$ when the cells were $60-70 \%$ confluent, the cells were transfected with shMTNR1B-1 (50 nM), shMTNR1B-2 (50 nM), shMTNR1B-3 (50 nM) or negative control in serum-free medium using Lipofectamine $3000^{\mathrm{TM}}$ (Thermo Fisher Scientific, Inc.) according to the manufacturer's protocol. Following incubation for $12 \mathrm{~h}$ at $37^{\circ} \mathrm{C}$, the medium in each well was then replaced with DMEM, containing $15 \%$ heat-inactivated FBS for another $48 \mathrm{~h}$. Following transfection, green fluorescence was used to observe the transduction efficiency.

GSIS in MIN6 cells in vitro. The MIN6 cells were starved with DMEM (0.1\% BSA and $3 \mathrm{mM}$ glucose) overnight. Next, the cells were starved again with Krebs-Ringer Bicarbonate buffer containing $125 \mathrm{mM} \mathrm{NaCl}, 4.74 \mathrm{mM} \mathrm{KCl}, 1 \mathrm{mM} \mathrm{CaCl}$,

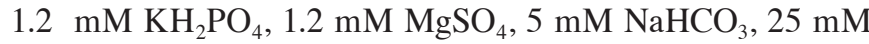
HEPES (pH 7.4) and $3 \mathrm{mM}$ glucose for $1 \mathrm{~h}$. The medium was then changed to KRB with either 3 or $25 \mathrm{mM}$ glucose. The medium was collected after $1 \mathrm{~h}$, and the insulin concentration was measured using the aforementioned ELISA kit.
Statistical analysis. For statistical evaluation and the significance testing of differences, the results are expressed as the mean \pm standard error of the mean. The nonparametric MannWhitney U test was performed with GraphPad software (version 6.0c; GraphPad Software, Inc., La Jolla, CA, USA). P<0.05 was considered to indicate a statistically significant difference. Each experiment was performed for more than 3 times.

\section{Results}

Exogenous melatonin inhibits the expression of insulin $m R N A$ in MIN6 cells. To characterize the influence of melatonin on insulin gene expression, MIN6 cells were treated with $0.01,0.1$, 1,10 or $100 \mu \mathrm{M}$ melatonin for 3 or $6 \mathrm{~h}$. Firstly, the mRNA levels of Ins1 were evaluated. Melatonin inhibited Ins1 gene expression potently and more strongly at the 6 -h time point compared with the 3-h time point (Fig. 1A and B). Melatonin decreased Ins1 mRNA expression with a nadir at $1 \mu \mathrm{M}$ in dose-response experiments where Ins1 mRNA was significantly reduced by $67 \pm 7$ and $81 \pm 3 \%$ at 3 and $6 \mathrm{~h}$, respectively, compared with that in the untreated control cells (Fig. 1A and B). Secondly, the impact of melatonin on Ins2 expression was investigated. Notably, melatonin was observed to exert much weaker effects on the expression of Ins 2 than on the expression of Ins1 (Fig. 1Cand D). Melatonin significantly decreased Ins2 

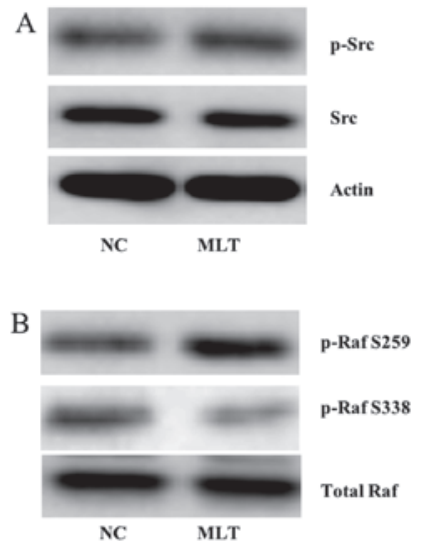
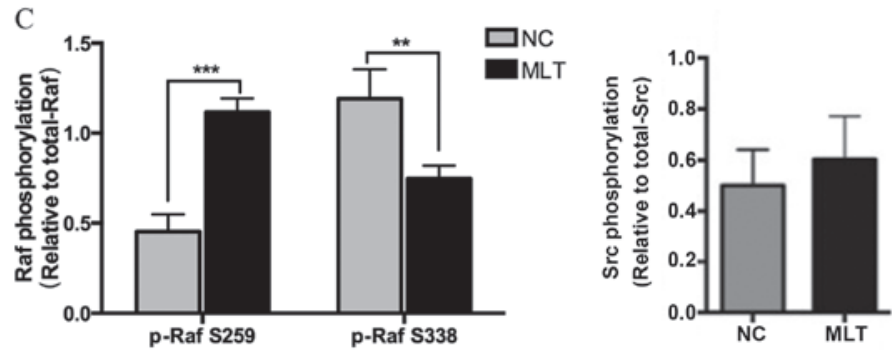

Figure 2. Impact of melatonin on the activities of Src and Raf-1. MIN6 cells were exposed to $1 \mu \mathrm{M}$ melatonin for $3 \mathrm{~h}$, and then the phosphorylation of (A) Src and (B) Raf-1 was evaluated by western blot analysis. (C) Relative phosphorylation levels of Raf. ${ }^{* *} \mathrm{P}<0.01,{ }^{* * * *} \mathrm{P}<0.001$ as indicated. NC, negative control; MLT, melatonin; $\mathrm{p}$, phosphorylated.
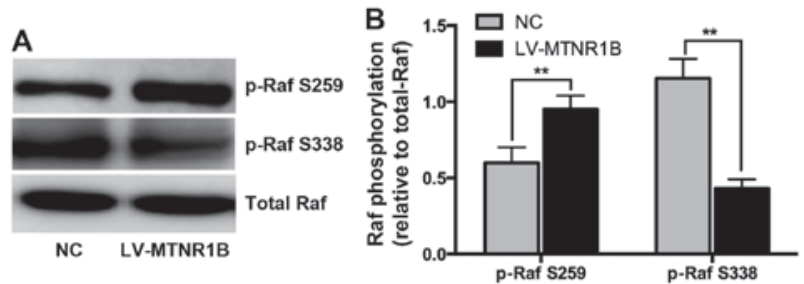

C

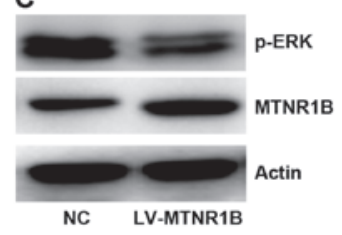

D

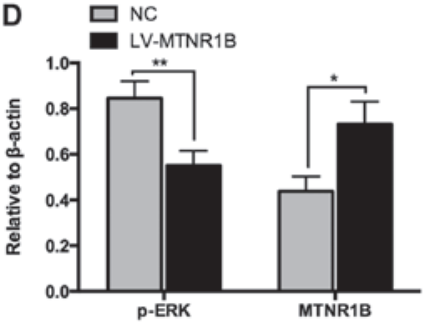

Figure.3 Effects of MTNR1B overexpression on the phosphorylation of Raf-1 and ERK1/2. LV-MTNR1B was transfected into MIN6 cells for $48 \mathrm{~h}$, and then the cells were treated with $1 \mu \mathrm{M}$ melatonin for an additional $3 \mathrm{~h}$. Western blot analysis was performed to detect the phosphorylation levels of (A and B) Raf-1 relative to total-Raf and (C and D) ERK1/2 relative to $\beta$-actin. (A) Representative western blots and (B) quantification of Raf-1 phosphorylation; (C) representative western blots and (D) quantification of ERK1/2 phosphorylation and MTNR1B. "P<0.05 and ${ }^{* *} \mathrm{P}<0.01$ as indicated. MTNR1B, melatonin receptor 1B; LV-MTNR1B, lentivirus overexpressing MTNR1B; ERK, extracellular signal-regulated kinase; $p$, phosphorylated; $\mathrm{NC}$, negative control.

mRNA expression by $12 \pm 1.6 \%$ when applied at a concentration of $1 \mu \mathrm{M}$ for $3 \mathrm{~h}$ when compared with the untreated control (Fig. 1C). There was also a $10 \pm 3.8 \%$ reduction of Ins 2 mRNA expression following the 6-h treatment with $1 \mu \mathrm{M}$ melatonin, but this reduction was not significant $(\mathrm{P}=0.057$; Fig. 1D).

In order to investigate the effects of melatonin on the secretion of insulin by the MIN6 cells, the insulin concentrations in the culture medium were measured using ELISA. The results demonstrated that treatment with various concentrations of melatonin for either 3 or $6 \mathrm{~h}$ had no effect on the quantity of insulin secreted by the MIN6 cells (Fig. 1E and F). In some cases, MIN6 cells exhibit weak or no responsiveness to stimuli such as glucose (20). To validate the responsiveness of the MIN6 cells to stimuli in the present study, in vitro GSIS experiments were performed. The results demonstrated that $25 \mathrm{mM}$ glucose significantly increased insulin secretion by 1.78 -fold compared

with $3 \mathrm{mM}$ glucose (Fig. 1G), indicating the satisfactory responsiveness of the MIN6 cells used in the present study to stimuli.

Melatonin inhibits the activation of Raf-1 in MIN6 cells. To investigate whether melatonin is capable of regulating the MAPK signaling pathway in MIN6 cells, the activities of two components of the pathway, namely Src and Raf-1 were evaluated. Western blot analysis revealed that treatment with $1 \mu \mathrm{M}$ melatonin for $3 \mathrm{~h}$ did not change the phosphorylation levels of Src (Fig. 2A). A study by Alejandro et al (15) demonstrated that Raf-1 is activated by dephosphorylation at serine 259 and phosphorylation at serine 338 in human islets, mouse islets and MIN6 cells. The phosphorylation levels at the Ser338 and Ser259 sites of Raf-1 were detected in the present study. The results indicated that the phosphorylation of Raf-1 at the promotional site Ser338 was significantly decreased by melatonin; the phosphorylation of Raf-1 at the inhibitory site Ser259, however, was significantly increased (Fig. 2B and C), which suggests that the activation of Raf-1 was repressed by the administration of melatonin.

Melatonin acts via MTNR1B and the Raf-1/ERK signaling pathway. The aforementioned results show that melatonin repressed the activation of Raf-1 (Fig. 2). In order to clarify whether MTNR1B participates in the melatonin-induced regulation of Raf-1 activity, MTNR1B was overexpressed and silenced, respectively, in MIN6 cells, and then the regulation of the activities of Raf-1 and ERK by melatonin was investigated. MIN6 cells were transfected with lentivirus overexpressing MTNR1B or shRNA targeting MTNR1B for $48 \mathrm{~h}$, treated with $1 \mu \mathrm{M}$ melatonin for $3 \mathrm{~h}$, and then the levels of phosphorylated Raf-1 and ERK were detected. The overexpression of MTNR1B resulted in decreased phosphorylation of Raf-1 at Ser338 and increased phosphorylation at Ser259 (Fig. 3A and B), along with reduced phosphorylation of ERK (Fig. 3C and D), indicating that inactivation of the Raf-1/ERK signaling pathway had occurred. By contrast, the knockdown of MTNR1B led to the activation of Raf-1/ERK signaling due to increased phosphorylation of Raf-1 at Ser338, decreased phosphorylation of Raf-1 at Ser259 as well as increased phosphorylation of ERK (Fig. 4A-D).

To determine whether MTNR1B was involved in the melatonin-induced regulation of insulin expression, Ins1 and 
A

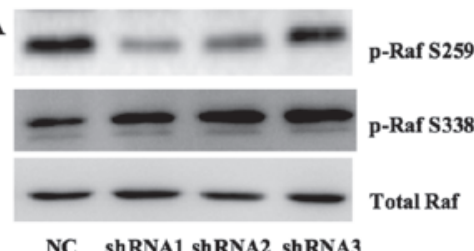

NC ShRNA1 shRNA2 shRNA3

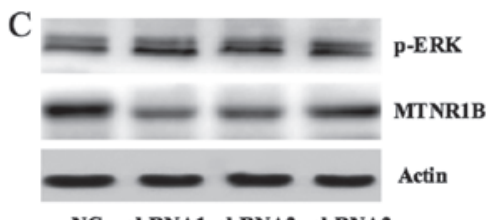

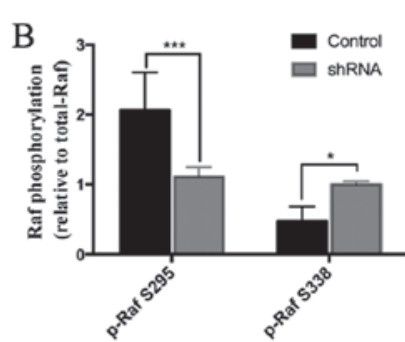

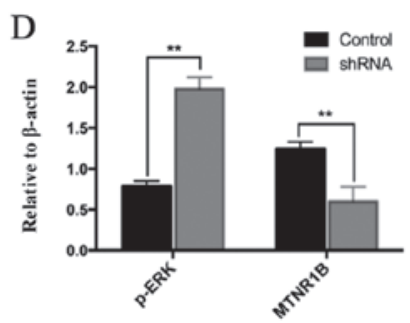

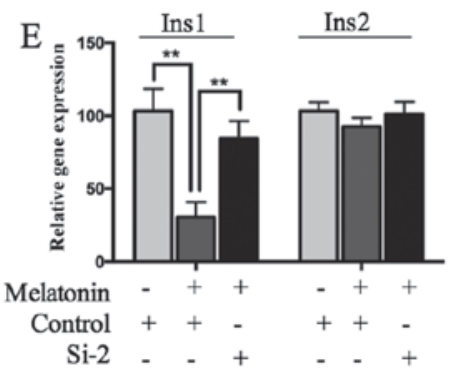

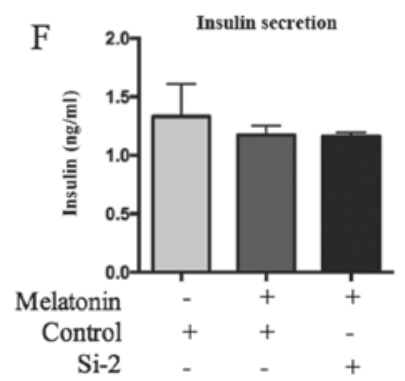

Figure 4. MIN6 cells were transfected with MTNR1B shRNA and control shRNA for $48 \mathrm{~h}$, and then the cells were treated with $1 \mu \mathrm{M}$ melatonin for an additional 3 h. (A and B) Phosphorylation of Raf-1 and (C and D) ERK1/2 were investigated using western blot analysis. (A) Representative western blots and (B) quantification of Raf-1 phosphorylation; (C) representative western blots and (D) quantification of ERK1/2 phosphorylation. (E) Ins1 and Ins2 gene expression as well as (F) insulin secretion were detected using reverse transcription-quantitative polymerase chain reaction and ELISA, respectively. $\mathrm{P}<0.05$, ${ }^{* *} \mathrm{P}<0.01$ and ${ }^{* * *} \mathrm{P}<0.001$, as indicated. MTNR1B, melatonin receptor $1 \mathrm{~B}$; shRNA, short hairpin RNA; ERK, extracellular signal-regulated kinase; p, phosphorylated; Ins1, insulin 1; Ins2, insulin 2; NC, negative control.

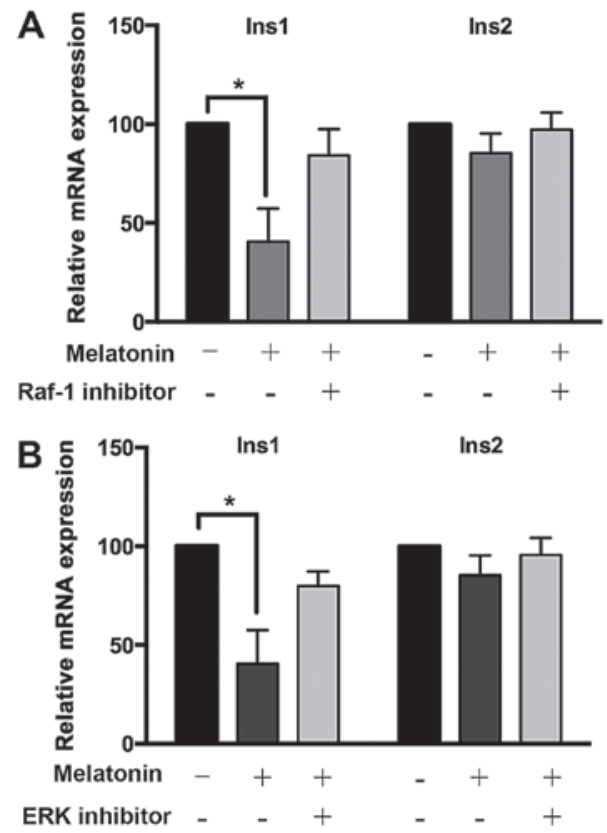

Figure 5. Effect of inhibition of (A) Raf-1 or (B) ERK activity on melatonin-regulated insulin gene expression. MIN6 cells were cultured with $5 \mu \mathrm{M}$ Raf-1 inhibitor GW5074, or $10 \mu \mathrm{M}$ ERK inhibitor U0126 for $30 \mathrm{~min}$ prior to $1 \mu \mathrm{M}$ melatonin administration for $3 \mathrm{~h}$. RNA was extracted and then the expression levels of Ins1 and Ins2 were determined by reverse transcription-quantitative polymerase chain reaction; ERK, extracellular signal-regulated kinase; Ins1, insulin 1; Ins2, insulin $2,{ }^{*} \mathrm{P}<0.05$ as indicated.

Ins2 gene expression was detected following the knockdown of MTNR1B expression, and the insulin levels in the culture medium were also measured. The data indicated that following the knockdown of MTNR1B, the effects of melatonin on Ins1 and Ins2 expression were totally attenuated (Fig. 4E), suggesting that melatonin regulated insulin gene expression

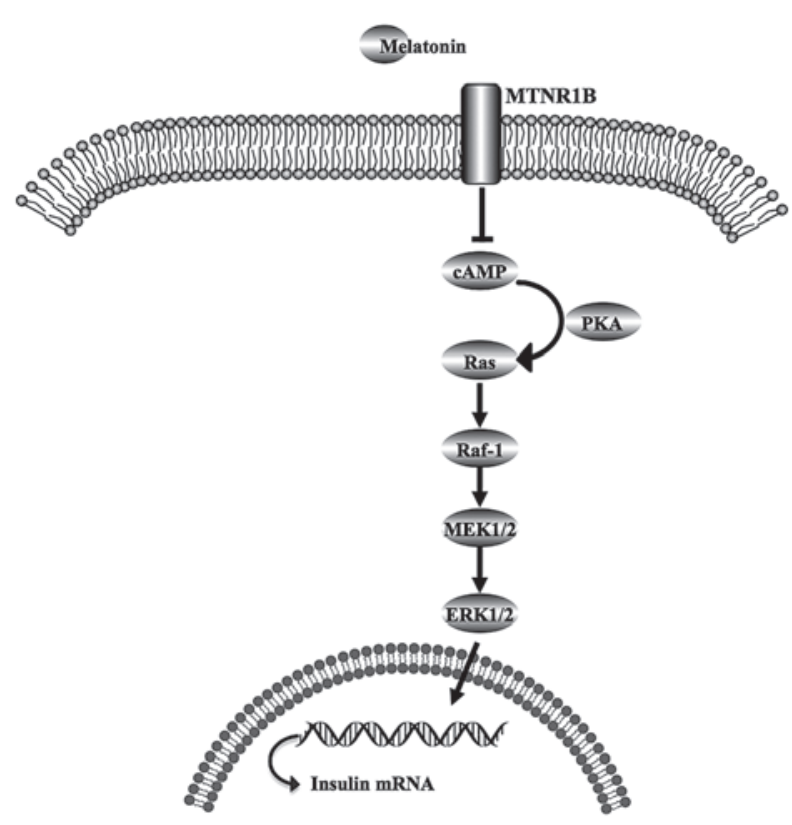

Figure 6. Proposed schematic for the melatonin/MTNR1B/Raf-1/ERK signaling pathway in MIN6 cells. Melatonin binds to the MT2 receptor followed by reduced cAMP production and PKA inhibition. In turn, this inactivates the Ras/Raf-1/ERK pathway, eventually decreasing insulin gene transcription. MTNR1B, melatonin receptor 1B; MT2, melatonin 2; cAMP, cyclic adenosine monophosphate; PKA, cAMP-dependent protein kinase; MEK, migotenactivated protein kinase kinase; ERK, extracellular signal-regulated kinase.

via MTNR1B. Insulin secretion by the cells was not affected by the manipulation of MTNR1B (Fig. 4F), consistent with the observation that melatonin exerted no effects on insulin secretion (Fig. 1E and F).

To identify whether melatonin exerted its effect on insulin gene expression through the Raf-1/ERK signaling pathway, the impact 
of melatonin on Ins1 and Ins2 expression was investigated after blocking the activity of Raf-1 and ERK using the chemical inhibitors GW5074 and U0126, respectively. Compared with the blank group, melatonin significantly suppressed the expression of Ins1 mRNA; however, when the activity of Raf-1 or ERK was blocked, the effect of melatonin on Ins1 mRNA levels was markedly attenuated (Fig. 5). The mRNA levels of Ins2 were decreased weakly by melatonin administration, and the two inhibitors slightly attenuated this effect of melatonin (Fig. 5). These data indicate that melatonin regulates the mRNA levels of Ins1 and Ins2 via the Raf-1/ERK signaling pathway.

\section{Discussion}

The study of melatonin-insulin interactions has revealed an inverse association between these two hormones (21). As previously mentioned, type 2 diabetic rats and humans exhibit increased plasma levels of insulin, and decreased melatonin levels $(10,11)$. Type 1 diabetic rats exhibit extremely reduced levels or the absence of insulin, but statistically significant increases in melatonin levels (22). These results are in agreement with observations that the pinealectomy of rodents caused hyperinsulinemia (23), and that following perfusion with melatonin, stimulated insulin secretion was inhibited in the pancreatic islets of normoglycemic Wistar and type 2 diabetic Goto-Kakizaki rats (24). Ramracheya et al (25) observed that melatonin inhibits glucose-stimulated insulin release from MIN6 cells. In the present study, the effects of melatonin on the expression of Ins1 and Ins2 genes in MIN6 cells were investigated and the results revealed that melatonin exerted a potent inhibitory effect on Ins1 mRNA, but a much weaker one on Ins 2 mRNA expression. The treatment of MIN6 cells with $1 \mu \mathrm{M}$ melatonin for $6 \mathrm{~h}$ reduced Ins1 mRNA expression by $81 \pm 3 \%$. The maximum effect of melatonin on Ins 2 mRNA expression was observed following incubation with $1 \mu \mathrm{M}$ melatonin for $3 \mathrm{~h}$, with a reduction of $12 \pm 1.6 \%$. The two mouse preproinsulin genes are located at different chromosomes, at chromosome 19 for Ins1 and chromosome 7 for Ins 2 , respectively (26). Regarding the disparity of the response to melatonin between Ins1 and Ins2, it may be speculated that melatonin preferentially regulated Ins1 expression. In addition to the expression of insulin at the genetic level, the regulation of the secretion of insulin by melatonin was also investigated in the present study. Notably, the results demonstrated that the treatment of MIN6 cells with different concentrations of melatonin for 3 or $6 \mathrm{~h}$ had no effect on the amount of insulin secreted by the cells. However, when the MIN6 cells were cultured in DMEM with $25 \mathrm{mM}$ glucose, the high concentration of glucose potently stimulated insulin secretion. It may be assumed that the high concentration of glucose came up with a high threshold for insulin secretion to other stimuli, which may have resulted in the MIN6 cells being unresponsive to melatonin. Previous studies concerning the impact of melatonin on insulin secretion are conflicting. Although the inhibitory effect of melatonin is predominant $(27,28)$, there are studies indicating that melatonin has neutral or stimulatory effects on insulin secretion $(29,30)$.

GWAS have revealed that the gene for the MT2 receptor is a locus with a high and reproducible association with a higher risk of impaired insulin secretion and increased fasting glucose levels $(2,3)$. The transcriptional and protein levels of MT1 and MT2 have been demonstrated to be significantly higher in the pancreatic tissues from patients with T2DM compared with those from metabolically healthy controls (31). These results are in accordance with the detection of increased MT2 receptor mRNA expression in the islets of individuals carrying the T2DM risk allele (3). A European cohort study (32) identified that rare MTNR1B variants causing impairment of the function of MTNR1B contributed to type 2 diabetes. It may be hypothesized that melatonin, when combined with the functional impairment of MTNR1B, would exert a more pronounced effect on the increased risk of T2DM.

The mechanism by which melatonin affects the stimulation of insulin secretion through MT2 is unclear. According to Picinato et al (33), melatonin regulates the growth and differentiation of pancreatic cells by activating two intracellular signaling pathways: PI3K/Akt and MEK/ERK. Therefore, the impact of melatonin on the MAPK signaling pathway was investigated in the present study.

MT receptors have been reported to couple with Gio-proteins, which inhibit the production of cyclic adenosine monophosphate (cAMP) (34). Melatonin has been shown to reduce the production cAMP in INS1 cells, resulting in diminished insulin release (30). It is well established that cAMP and its principal target, the cAMP-dependent protein kinase (PKA), are extensively involved in the impact of hormones on metabolic pathways, as well as cell growth and proliferation (35). MAPK, also known as ERK, is a target of cAMP that is activated or inhibited by cAMP in a cellspecific manner (35). ERKs are intracellular signaling molecules involved in the regulation of cell proliferation and other cellular functions (36). It has been reported that ERK1/2 are required for the stimulatory effect of glucose on insulin gene transcription (14). To elucidate the mechanism underlying the impact of melatonin on insulin transcription and secretion, the regulation of the MAPK signaling pathway by melatonin and its receptor MTNR1B was investigated. The Src/Ras-related protein 1/B-Raf and Ras/Raf-1 pathways are two upstream cascades converging on ERKs (35). Insulin secretion has been shown to be significantly reduced in mouse $\beta$-cell Raf-1-knockout islets (37). An association of Src kinases with insulin secretion has also been reported (16). Therefore, whether the activity of Src and/or Raf-1 is regulated by melatonin was investigated in the present study. The data demonstrated that the phosphorylation of Src was not affected by melatonin, whereas Raf-1 was strongly inactivated by the administration of melatonin to MIN6 cells, implying that the effect of melatonin on the MAPK pathway was mediated by Raf-1, not via Src. In a study by Kowluru et al (38), the overexpression of Raf-1 led to a significant glucose-mediated activation of ERK1/2 in INS 832/13 cells, and the pharmacological inhibition of Raf- 1 kinase markedly reduced the stimulatory effects of glucose on ERK1/2 phosphorylation and insulin secretion. In the present study, it was observed that following the inhibition of the activity of Raf-1 or ERK using chemical inhibitors, the effects of melatonin on the mRNA expression of Ins1 and Ins2 in MIN6 cells were attenuated, suggesting the involvement of the Raf-1/ERK pathway in melatonin-regulated insulin gene transcription. Since the majority of melatonin's functions are fulfilled through its receptors (39), it was next determined whether the MT2 receptor participated in the melatonin-induced regulation of Raf-1/ERK signaling. It was observed that the overexpression of MTNR1B significantly decreased Raf-1 and ERK activities in the melatonin-treated MIN6 cells, whereas the knockdown of MTNR1B resulted in significant activation of Raf-1/ERK signaling. Notably, following MTNR1B silencing, the effect of melatonin on insulin gene transcription was totally attenuated. Based on all the data in the 
present study, a melatonin/MT2 receptor/Raf-1/ERK signaling pathway for the regulation of insulin gene expression in MIN6 cells is proposed, which is illustrated in Fig. 6. In this, melatonin binds to the MT2 receptor, which reduces cAMP production and PKA inhibition, in turn inactivating the Ras/Raf-1/ERK pathway, and eventually decreasing insulin gene transcription.

In conclusion, the present study provides evidence that melatonin inhibits insulin gene expression in MIN6 mouse pancreatic $\beta$-cells, but has no effect on insulin secretion. The present data also indicate for the first time that melatonin, via its receptor MT2, exerts an inhibitory effect on the Raf-1/ERK pathway in MIN6 cells.

\section{Acknowledgements}

The present study was supported by grants from the National Natural Science Foundation of China (grant nos. 81270903 to Jie Wen and 81370936 to Xuanchun Wang) and the Natural Science Foundation of Shanghai City (grant no. 10ZR1405500 to Jie Wen). The study was also sponsored by grants from Shanghai Pujiang Program (grant no. 16PJ1401700 to Xuanchun Wang) and the Science and Technology Commission of Shanghai Municipality (grant no. 16140901200 to Xuanchun Wang).

\section{References}

1. Peschke E, Bähr I and Mühlbauer E: Experimental and clinical aspects of melatonin and clock genes in diabetes. J Pineal Res 59: 1-23, 2015.

2. Simonis-Bik AM, Nijpels G, van Haeften TW, Diamant M, Kramer MH, Heine RJ, et al: Gene variants in the novel type 2 diabetes loci CDC123/CAMK1D, THADA ADAMTS9, BCL11A, and MTNR1B affect different aspects of pancreatic beta-cell function. Diabetes 59: 293-301, 2010

3. Lyssenko V, Nagorny CL, Erdos MR, Wierup N, Jonsson A, Spégel P, Bugliani M, Saxena R, Fex M, Pulizzi N, et al: Common variant in MTNR1B associated with increased risk of type 2 diabetes and impaired early insulin secretion. Nat Genet 41: 82-88, 2009.

4. Rönn T, Wen J, Yang Z, Lu B, Du Y, Groop L, Hu R and Ling C: A common variant in MTNR1B, encoding melatonin receptor $1 \mathrm{~B}$, is associated with type 2 diabetes and fasting plasma glucose in Han Chinese individuals. Diabetologia 52: 830-833, 2009.

5. Stehle JH, Saade A, Rawashdeh O, Ackermann K, Jilg A, Sebestény T and Maronde E: A survey of molecular details in the human pineal gland in the light of phylogeny, structure, function and chronobiological diseases. J Pineal Res 51: 17-43, 2011.

6. Sharma S, Singh H, Ahmad N, Mishra P and Tiwari A: The role of melatonin in diabetes: Therapeutic implications. Arch Endocrinol Metab 59: 391-399, 2015.

7. Nagorny CL, Sathanoori R, Voss U, Mulder H and Wierup N: Distribution of melatonin receptors in murine pancreatic islets. J Pineal Res 50: 412-417, 2011

8. Mühlbauer E, Gross E, Labucay K, Wolgast S and Peschke E: Loss of melatonin signalling and its impact on circadian rhythms in mouse organs regulating blood glucose. Eur J Pharmacol 606: 61-71, 2009.

9. Bazwinsky-Wutschke I, Wolgast S, Mühlbauer E, Albrecht E and Peschke E: Phosphorylation of cyclic AMP-response element-binding protein (CREB) is influenced by melatonin treatment in pancreatic rat insulinoma $\beta$-cells (INS-1). J Pineal Res 53: 344-357, 2012.

10. Peschke E, Hofmann K, Pönicke K, Wedekind D and Mühlbauer E: Catecholamines are the key for explaining the biological relevance of insulin-melatonin antagonisms in type 1 and type 2 diabetes. J Pineal Res 52: 389-396, 2012.

11. Bach AG, Mühlbauer E and Peschke E: Adrenoceptor expression and diurnal rhythms of melatonin and its precursors in the pineal gland of type 2 diabetic goto-kakizaki rats. Endocrinology 151: 2483-2493, 2010

12. Kim TK, Lee JS, Jung HS, Ha TK, Kim SM, Han N, Lee EJ, Kim TN, Kwon MJ, Lee SH, et al: Triiodothyronine induces proliferation of pancreatic beta-cells through the MAPK/ERK pathway. Exp Clin Endocrinol Diabetes 122: 240-245, 2014.

13. Beith JL, Alejandro EU and Johnson JD: Insulin stimulates primary beta-cell proliferation via Raf-1 kinase. Endocrinology 149: 2251-2260, 2008.

14. Lawrence MC, Jivan A, Shao C, Duan L, Goad D, Zaganjor E, Osborne J, McGlynn K, Stippec S, Earnest S, et al: The roles of MAPKs in disease. Cell Res 18: 436-442, 2008.
15. Alejandro EU, Kalynyak TB, Taghizadeh F, Gwiazda KS, Rawstron EK, Jacob KJ and Johnson JD: Acute insulin signaling in pancreatic beta-cells is mediated by multiple Raf- 1 dependent pathways. Endocrinology 151: 502-512, 2010.

16. Liu Q, Wang R, Zhou H, Zhang L, Cao Y, Wang X and Hao Y: SHIP2 on pI3K/Akt pathway in palmitic acid stimulated islet $\beta$ cell. Int J Clin Exp Med 8: 3210-3218, 2015.

17. Stewart AF, Hussain MA,García-Ocaña A, Vasavada RC, Bhushan A, Bernal-Mizrachi E and Kulkarni RN: Human $\beta$-cell proliferation and intracellular signaling: Part 3. Diabetes 64: 1872-1885, 2015.

18. Pardo FN, Altirriba J, Pradas-Juni M, García A, Ahlgren U, Barberà A, Slebe JC, Yáñez AJ, Gomis R and Gasa R: The role of Raf-1 kinase inhibitor protein in the regulation of pancreatic beta cell proliferation in mice. Diabetologia 55: 3331-3340, 2012.

19. Livak KJ and Schmittgen TD: Analysis of relative gene expression data using real-time quantitative PCR and the 2(-Delta Delta C(T)) Method. Methods 25: 402-408, 2001.

20. Cheng K, Delghingaro-Augusto V, Nolan CJ, Turner N, Hallahan N, Andrikopoulos S and Gunton JE: High passage MIN6 cells have impaired insulin secretion with impaired glucose and lipid oxidation. PLoS One 7: e40868, 2012.

21. Mühlbauer E, Albrecht E, Bazwinsky-Wutschke I and Peschke E: Melatonin influences insulin secretion primarily via MT(1) receptors in rat insulinoma cells (INS-1) and mouse pancreatic islets. J Pineal Res 52: 446-459, 2012.

22. Peschke E, Wolgast S, Bazwinsky I, Pönicke K and Muhlbauer E: Increased melatonin synthesis in pineal glands of rats in streptozotocin induced type 1 diabetes. J Pineal Res 45: 439-448, 2008.

23. Nishida S, Segawa T, Murai I and Nakagawa S: Long-term melatonin administration reduces hyperinsulinemia and improves the altered fatty-acid compositions in type 2 diabetic rats via the restoration of Delta-5 desaturase activity. J Pineal Res 32: 26-33, 2002.

24. Peschke E, Schucht H and Mühlbauer E: Long-term enteral administration of melatonin reduces plasma insulin and increases expression of pineal insulin receptors in both Wistar and type 2-diabetic Goto-Kakizaki rats. J Pineal Res 49: 373-381, 2010.

25. Ramracheya RD, Muller DS, Squires PE, Brereton H, Sugden D, Huang GC, Amiel SA, Jones PM and Persaud SJ: Function and expression of melatonin receptors on human pancreatic islets. J Pineal Res 44: 273-279, 2008.

26. Wentworth BM,Schaefer IM, Villa-Komaroff L and Chirgwin JM: Characterization of the two nonallelic genes encoding mouse preproinsulin. J Mol Evol 23: 305-312, 1986.

27. Peschke E, Peschke D, Hammer T and Csernus V: Influence of melatonin and serotonin on glucose-stimulated insulin release from perifused rat pancreatic islets in vitro. J Pineal Res 23: 156-163, 1997.

28. Picinato MC,HaberEP,Cipolla-Neto J, CuriR, de Oliveira Carvalho CR and Carpinelli AR: Melatonin inhibits insulin secretion and decreases PKA levels without interfering with glucose metabolism in rat pancreatic islets. J Pineal Res 33: 156-160, 2002.

29. Frankel BJ and Strandberg MJ: Insulin release from isolated mouse islets in vitro: No effect of physiological levels of melatonin or arginine vasotocin. J Pineal Res 11: 145-148, 1991.

30. Peschke E, Bach AG and Mühlbauer E: Parallel signaling pathways of melatonin in the pancreatic beta-cell. J Pineal Res 40: 184-191, 2006.

31. Peschke E, Stumpf I, Bazwinsky I, Litvak L, Dralle H and Mühlbauer E: Melatonin and type 2 diabetes - a possible link? J Pineal Res 42: 350-358, 2007.

32. Bonnefond A,ClémentN,FawcettK, Yengo L, VaillantE, Guillaume JL, Dechaume A, Payne F, Roussel R, Czernichow S, et al: Rare MTNR1B variants impairing melatonin receptor $1 \mathrm{~B}$ function contribute to type 2 diabetes. Nat Genet 44: 297-301, 2012.

33. Picinato MC, Hirata AE, Cipolla-Neto J, Curi R, Carvalho CR Anhê GF and Carpinelli AR: Activation of insulin and IGF-1 signaling pathways by melatonin through MT1 receptor in isolated rat pancreatic islets. J Pineal Res 44: 88-94, 2008.

34. Vanecek J: Cellular mechanisms of melatonin action. Physiol Rev 78: 687-721, 1998

35. Stork PJ and Schmitt JM: Crosstalk between cAMP and MAP kinase signaling in the regulation of cell proliferation. Trends Cell Biol 12: 258-266, 2002.

36. Pearson G, Robinson F, Beers Gibson T, Xu BE, Karandikar M, Berman K and Cobb MH: Mitogen-activated protein (MAP) kinase pathways: Regulation and physiological functions. Endocr Rev 22: 153-183, 2001

37. Alejandro EU, Lim GE, Mehran AE, Hu X, Taghizadeh F Pelipeychenko D, Baccarini M and Johnson JD: Pancreatic $\beta$-cell Raf-1 is required for glucose tolerance, insulin secretion, and insulin 2 transcription. FASEB J 25: 3884-3895, 2011.

38. Kowluru A, Veluthakal R, Rhodes CJ, Kamath V, Syed I and Koch BJ: Protein farnesylation-dependent Raf/extracellular signal-related kinase signaling links to cytoskeletal remodeling to facilitate glucose-induced insulin secretion in pancreatic beta-cells. Diabetes 59: 967-977, 2010

39. Boutin JA, Audinot V, Ferry G and Delagrange P: Molecular tools to study melatonin pathways and actions. Trends Pharmacol Sci 26: 412-419, 2005. 